\title{
Digitalizando o cuidado: mulheres e novas codificações para a ética hacker*
}

\author{
Graciela Natansohn** \\ Josemira Reis***
}

\section{Resumo}

A partir do mapeamento de ações desenvolvidas por grupos feministas para a segurança digital, chamados de "cuidados digitais", analisamos as suas estratégias, que surgem em resposta às opacidades $e$ injustiças algorítmicas, à pouca diversidade nos espaços tecnológicos $e$ ao crescimento das violências de gênero nos ambientes digitais. Neste texto vamos discutir um aspecto deste hacktivismo (autodenominado de hackfeminista), o dos cuidados digitais, a partir da perspectiva feminista da ética do cuidado (Gilligan, 2013; Hirata e Debert, 2016), confrontando-a com os princípios da ética hacker (Levy, 1994; Himanen, 2001).

Palavras-chave: Ética Hacker, Ética do Cuidado, Hackfeminismo, Brecha Digital, Tecnoativismo.

* Recebido em 17 de setembro de 2019, aceito em 03 de março de 2020.

** Docente e pesquisadora da Faculdade de Comunicação da Universidade Federal da Bahia (UFBA), e do PósCom/UFBA e Coordenadora do grupo de Pesquisa em Gênero, Tecnologias Digitais e Cultura (GIG@), Salvador, Bahia, Brasil graciela@ufba.br/ ORCID 0000-0003-3404-4522

*** Doutoranda do Programa de Pós-Graduação em Comunicação e Cultura Contemporâneas, da Universidade Federal da Bahia (UFBA), pesquisadora do grupo Gênero, Tecnologias Digitais e Cultura (GIG@), Salvador, Bahia, Brasil. josemirareis@gmail.com / ORCID: 0000-0002-9696-5987 
Digitizing Care: Women and New Codingsfor Hacker Ethics

\begin{abstract}
Based on a mapping of actions by feminist groups to enhance digital security, called "digital care", we analyze strategies that arise in response to algorithmic opacities and injustices, the lack of diversity in technological spaces and growing gender-based violence in digital environments. We discuss an aspect of this hacktivism (by those who call themselves hackfeminists), that of digital care, considering the perspective of the feminist ethics of care (Gilligan, 2013; Hirata and Debert, 2016), comparing this with the principles of hacker ethics (Levy, 1994; Himanen, 2001).

Keyword: Hacker Ethics, Ethics of Care, Hackfeminism, Digital Divide, Technoactivism.
\end{abstract}




\section{Apresentação}

Nos últimos dez anos temos visto proliferar uma série de iniciativas organizadas por agrupamentos autodenominados hackfeministas (Toupin, 2014; Fox, Ulgado e Rosner, 2015; Araújo, 2018; Reis e González Ramos, 2019). Esses grupos, para além de problematizar a ausência de diversidade nos processos de desenvolvimento, deliberação e circulação das tecnologias digitais, têm se ocupado, também, de reivindicar a internet como um direito humano. Para tanto, contestam e criticam os atuais direcionamentos que têm tomado a arquitetura das tecnologias de comunicação, cada vez mais orientada por processos de vigilância massiva e o recrudescimento das violências digitais contra as mulheres e grupos dissidentes.

Trata-se de coletivas ${ }^{1}$ com interesses diversos, que envolvem a produção material de recursos tecnológicos de base (sobretudo hardwares e softwares livres), a alfabetização digital, a criação de redes $e$ aplicativos autônomos $e$ seguros $e$, principalmente, o hackeamento dos aspectos androcêntricos das relações sociotécnicas contemporâneas. Muitos desses grupos desenvolvem projetos locais, autogestionados, independentes, cooperativos $e$ gerenciados com perspectivas feministas interseccionais. Na busca de particularidades comuns que nos permitam prefigurá-los como parte de um movimento ou, talvez, um protomovimento social, com capacidade de contestação organizada, pesquisamos seus modos de funcionamento, suas produções discursivas $e$ estratégicas.

Uma das práticas mais difundidas por esses grupos é o trabalho sobre os cuidados de si e das outras, para prevenir e agir perante ataques misóginos. Avaliando estas práticas e os processos de apropriação que essas coletivas estabelecem, tanto no plano da técnica como da cultura, é possível perceber os deslocamentos

${ }^{1}$ Optamos em nossa escrita por preservar os usos gramaticais legitimados pelas comunidades estudadas, quando feminizam termos comuns ao universo computacional e ativista, daí o uso de termos como coletivas, computadoras, servidoras, etc. 
semiótico-materiais promovidos por essas mulheres, no sentido de buscar respostas aos riscos que os novos códigos sociotécnicos têm implicado para a segurança, privacidade, representação social $e$ intimidade. Tais ações adquirem formatos diversos, como: manuais para ativistas e demais usuárias fazerem download; aplicativos ou textos com recomendações para práticas seguras; bots, para amplificar a participação e mobilização política; e o provimento de uma série de ferramentas de comunicação - emails, chats, troca de arquivos, hospedagem de sites e etherpads -, devidamente criptografadas de ponta a ponta, com o intuito de aumentar a segurança, tanto em nível individual como das redes de socialização dessas mulheres.

Ainda que parte do ativismo feminista digital, essas ações não se limitam a serem publicadas e divulgadas em ambientes online. Oficinas e cursos presenciais também são realizados por muitas coletivas com apoio de ONGs, em diferentes locais e sob cuidados extremos, para manter o sigilo das participantes, pois muitas são militantes dos direitos humanos em países que penalizam qualquer dissidência política. Além disso, nota-se esforços no sentido de ressignificar práticas hackers, a partir de endereçamentos feministas. Assim, diferentemente dos tradicionais hackathons (maratonas de programação), as melhores soluções tecnológicas de uma hackathona feminista não devem ser julgadas só por sua eficiência, mas precisam obedecer a parâmetros de codificação que priorizem a equidade de gênero e raça ou contribuam para dirimir dilemas a esse tópico relacionados. Já as criptoparties feministas, além de promover de modo lúdico a formação de mulheres em temas como criptografia, autonomia $e$ privacidade, dedicam-se a problematizar, interseccionalmente, os sentidos que tais conceitos assumem para os corpos de indivíduos atravessados por diferentes experiências de raça, classe, gênero e território. E as editatonas de Wikipédia, mais do que se orientarem pela perspectiva de democratização do conhecimento, buscam visibilizar mais mulheres ou reescrever termos sem androcentrismos. 
Se concordamos que "os princípios políticos da Internet são desempenhados por sua arquitetura $e$ modo de funcionamento, $e$ que a maneira mais eficaz de fazer prevalecer tais ou quais princípios políticos e morais na rede passa por influenciar sua tomada de forma" (Vicentin, 2016:231), então a análise das estratégias de apropriação dessas infraestruturas por segmentos subalternizados mostra-se um profícuo campo para reflexão acerca dos dilemas éticos que orientam a codificação das relações de nosso tempo. O enviesamento dos códigos - construídos em perspectivas generificadas, racializadas e situadas (Haraway, 2004) - tem originado demandas pela transparência e justiça algorítmica (Zuboff, 2015; O'Neil, 2017). Ou seja, na era da digitalização não só o pessoal é político, mas também o código. Esse panorama impulsiona as ativistas digitais a tecer redes de ajuda $e$ solidariedade, invocando estratégias de colaboração $e$ acolhimento em rede, o que corrobora com as proposições analíticas de Maria Puig de la Bellacasa (2011) acerca da necessidade de incorporação de uma ética do cuidado por parte da tecnociência contemporânea.

Por isso, neste texto vamos discutir um aspecto deste ativismo hackfeminista, o dos cuidados digitais, a partir da perspectiva feminista da ética dos cuidados (Gilligan, 2013; Jaggar, 2014; Hirata e Debert, 2016; Zirbel, 2016) e da ética hacker (Levy, 1994; Himanen, 2001; Castells, 2003; Coleman e Golub, 2008), dos ciberfeminismos e tecnofeminismos (Wajcman, 2006; Natansohn, 2013; Haché, Cruells e Bosch, 2013; Toupin, 2014; Fox, Ulgado e Rosner, 2015) e dos estudos sociais feministas em ciência e tecnologia (Haraway, 2004).

A ética do cuidado sustenta-se na ideia de que todas as pessoas são susceptíveis de vulnerabilidades, fragilidades $e$ interdependência, e que as atividades que têm como objetivo proporcionar bem-estar e cuidar destas questões estão naturalizadas de tal forma que se ignoram as relações de gênero (principalmente de idade e de parentesco, as de classe são mais debatidas) que as sustentam. $\mathrm{O}$ conceito parte das críticas às práticas de cuidados domésticos na divisão social do trabalho, mas 
ao ampliar os cuidados para os fazeres tecnológicos, estas coletivas provocam ressignificações importantes também sobre o que se convencionou na literatura chamar de ética da cultura digital (Castells, 2003) ou ética hacker. Seguindo muitos dos princípios da tradição filosófica liberal, a ética digital ou hacker aparece nessa bibliografia sempre vinculada a valores como autonomia, meritocracia, abertura e compartilhamento. Os novos grupos hackfeministas, como veremos adiante, sugerem deslocamentos desses dois ethos (o dos cuidados e o hacker), onde elementos intrínsecos ao cuidado - o afeto, a preocupação com as vulnerabilidades - são enfatizados para olhar tanto a tecnologia, quanto os corpos e vidas.

Primeiro, apresentamos o fenômeno a partir dos quais vislumbramos as rupturas promovidas por essas coletivas com o hackerismo tradicional, isto é, mapeamos as estratégias de tecnoativismo realizadas como resposta aos dilemas vivenciados por essas mulheres, num cenário atual cujas relações simbólicoprodutivas, amparadas em processos massivos de coleta, predição e monetarização de dados, parecem contribuir para a proliferação $e$ aprofundamento de assimetrias e novas expressões de violência de gênero. Logo depois, as interpretamos à luz dos debates sobre a ética do cuidado e da ética hacker, já mencionadas.

\section{Mulheres e o hackeamento das violências de gênero das relações sociotécnicas}

Um dos temas que tem ocupado a mídia e o judiciário nos últimos anos tem sido a violência de gênero e o ódio misógino exercido mediante e através dos dispositivos eletrônicos, muito especialmente com os celulares. As relações sociais em ambientes digitais, numa sociedade patriarcal, não poderiam estar isentas de violência machista. E diagnósticos acerca dos diversos tipos de violências na internet vêm sendo feitos por organizações internacionais, como a Association for Progressive Communications/APC e, do Brasil, por associações civis como CodingRights e InternetLab que, em 2017, elaboraram um informe 
sobre violências contra as mulheres na internet com diagnósticos, soluções e desafios, para a relatora especial da ONU (CodingRights e Internetlab, 2017). Mapeamento de Reis e Natansohn (2017) mostra que a violência foi a temática central da intensa mobilização de mulheres que tomou os sites de redes sociais no Brasil $^{2}$, em 2015, e que foi batizada pela mídia como "primavera feminista".

$\mathrm{O}$ que se percebe, portanto, é que além de se organizarem para reivindicar transformações, as feministas têm lidado com a necessidade de criar estratégias de resistência às reconfigurações que assume a violência no ambiente digital. Fenômenos como ciberchantagem, cyberstalking, cyberbullying, doxing, divulgação de dados e imagens sem consentimento, trolls e todo tipo de ataques misóginos são alguns dos desafios que crescem, proporcionalmente às oportunidades geradas pelas tecnologias. Dados $^{3}$ (IPEA e FBSP, 2019; Oliveira, 2017; TGEU, 2019) também permitem ver como mulheres negras e trans ocupam situações de maior vulnerabilidade quando o tema é violência: feminicídio, violência doméstica, obstétrica e a mortalidade materna atingem principalmente este segmento. Para além de todas as problemáticas aqui elencadas, essas mulheres são, também, as que mais lidam com ataques online.

Ainda nestes últimos anos, à violência digital somam-se evidências sobre a coleta e mercantilização descontrolada dos dados pessoais em rede, que colocam em xeque o direito à privacidade $e$ intimidade das pessoas $e$ se constituem em mecanismos sofisticados de rastreamento e vigilância. Para

${ }^{2}$ A campanha \#primeiroassedio, por exemplo, teve mais de 11 milhões de buscas no Google.

${ }^{3} \mathrm{O}$ ano de 2017 registrou o maior índice de assassinato de mulheres em 10 anos (4.936). Dessas vítimas, mulheres negras eram o 66\%. Entre 2007 e 2017, o assassinato de mulheres negras cresceu 29,9\%. Mulheres negras também morrem mais de parto $(62 \%)$ e são mais atingidas pelas diversas expressões de violência obstétrica. Dos homossexuais e bissexuais que são alvo de violência no país, $59,5 \%$ são mulheres. E por dez anos (de 2008 a 2018) o país tem sido líder no ranking mundial dos que mais matam pessoas trans e quinto no do feminicídio. 
algumas autoras, estes mecanismos devem ser considerados como uma forma de violência digital (Natansohn e Goldsman, 2018). Ou seja, que é possível pensar que, para além dos seis níveis de violência identificados socialmente (física, psicológica, sexual, patrimonial, moral, simbólica), esta começa a se legitimar estruturalmente a partir de seus protocolos sociotécnicos, através da ação de atores não humanos, o que também exige outros esforços dos feminismos em nosso tempo. Por um lado, requer organizar-se para dar respostas aos dilemas sociais que atravessam o mundo violento; por outro, proteger-se de processos tecnológicos ocultos, sob forma de algoritmos obtusos, que têm mediado nossas relações com esse mundo.

A problemática da violência de gênero na atualidade não só se traslada para as tecnologias de informação e comunicação (TICs), mas passa a fazer parte, também, dos parâmetros de construção da arquitetura digital que conforma as relações contemporâneas. A preocupação com esse novo contexto de comodificação dos dados parece ter se tornado central, também, para a agenda tecnocientífica na atualidade. O Pew Research Internet Center (2017) divulgou relatório de uma escuta feita junto a cerca de 1.300 especialistas da área tecnológica, onde buscou delinear as principais projeções acerca dos impactos sociais da disseminação indiscriminada de algoritmos pelos próximos dez anos. O aumento da desigualdade social aparece como um dos dez principais problemas enxergados pelos tecnólogos, pesquisadores, empresários do ramo e líderes governamentais ouvidos na pesquisa. O receio é que, tanto algoritmos como o modo como olhamos para os dados que eles apresentam, privilegiem a narrativa de poucos - a de seus criadores, seus clientes potenciais $e$ as crenças que tais grupos transportam para os códigos -, em detrimento dos mais empobrecidos e daqueles cujas competências digitais encontram-se limitadas por situações de raça, gênero, classe, território, etc. Por isso, em tempos de crescente mobilização feminista e antirracista, importa observar as controvérsias que implicam reclamar transformações a partir da apropriação de artefatos não neutros, cujos códigos de conduta, 
ação e regulação se inscrevem a partir de um novo paradigma que tem se consolidado a partir da manipulação de dados, sob referenciais de demandas mercadológicas (Zuboff, 2015; Van Dijck, 2017).

É assim que ressurgem com força, nesta década, novas expressões do hackativismo feminista, que repensam o lugar do ativismo por outras vias, não limitadas à camada que permite a produção e divulgação de conteúdos na internet, senão que olha para o campo das infraestruturas lógicas e físicas, responsáveis pelas condições de existência das tecnologias como um todo. Também autodenominado como transhackfeministas, aderem ao feminismo em suas versões queer $e$ trans, enfatizam e promovem processos de autonomia tecnológica, comunitarismo, redes alternativas e livres e rejeitam as cumplicidades do big data ${ }^{4}$ com o modelo de negócios da internet, a partir de um enfoque interseccional.

Esse macro contexto até aqui delineado $e$ as observações apreendidas em nossas pesquisas de campo, levou-nos a colocar atenção sobre um conjunto de práticas que vêm cada vez mais se fazendo presentes nas estratégias das ativistas em rede nos últimos anos e que, geralmente, são nomeadas por suas partícipes de "cuidados digitais" ou "autocuidados" em rede.

O mapeamento inicial de coletivas e sítios web com ferramentas ou outros instrumentos para cuidado e segurança digital, realizado para nossas pesquisas, apresentou como resultado preliminar um conjunto de propostas do Brasil, obtidas mediante busca via palavras-chave - "cuidados digitais", "autocuidado", "care" - e mediante informantes-chave pertencentes aos grupos que temos seguido. A análise dos dados sugere que, apesar de estratégias múltiplas e geopoliticamente situadas, é possível compreender que os agrupamentos

${ }^{4}$ Big data é o campo que se dedica ao estudo sobre como tratar e analisar a grande quantidade de dados produzida nas relações digitais. 
hackfeministas no país têm concentrado seus esforços em três grandes eixos de ações a seguir apresentadas ${ }^{5}$.

Engajamento em ações para formação técnica $e$ visibilidade de mulheres na tecnologia - é neste eixo que as hackers brasileiras têm envidado mais esforços: no oferecimento de oficinas, cursos, bem como no incentivo à participação em eventos voltados para pensar o lugar do gênero na tecnologia - hackhatonas, participação em fóruns da área, etc. A extrema atenção a ações que envolvem o aumento numérico e visibilidade de mulheres na tecnologia tem a ver com traçar estratégias para subverter a tendência mundial à exacerbação da presença masculina e branca nos principais espaços de produção e governança digital. Além disso, a criação de espaços voltados para mulheres e pessoas LGBT +, busca propiciar a criação de redes de aprendizagem que encorajem o aprimoramento profissional, o protagonismo e o combate à naturalização de relações sexistas e misóginas que se mostram recorrentes em suas experiências de socialização no âmbito tecnológico.

Produção de manuais - prática bastante utilizada pelos coletivos hackers ligados à cultura do software livre e do código aberto, a produção de manuais e tutoriais geralmente tem o objetivo de documentar e democratizar o acesso à lógica de funcionamento dessas tecnologias desenvolvidas em rede. Para muitos/as hackers, o domínio da linguagem computacional é o meio pelo qual podemos produzir nossa própria informação $e$ sermos mais livres (Silveira, 2010). Logo, disponibilizar manuais gratuitos via internet é o modo de alcançar o máximo possível de pessoas. Em nossas investigações é possível perceber que hackfeministas têm se apropriado da lógica de produção de manuais para divulgar conteúdos que envolvem tanto o passo a passo para construção de tecnologias livres, como a divulgação de condutas de segurança que mulheres e ativistas devem atentar para se proteger nos ambientes digitais. Os nomes de tais

${ }^{5}$ Focamos no Brasil, mas existem redes distribuídas por toda América Latina atuando em estreita colaboração. 
iniciativas já se mostram bastante sugestivos: Currícula de Capacitación en Seguridad Digital Holística para Defensoras de Derechos Humanos ${ }^{6}$ (em espanhol, árabe e inglês); Guia prática de estratégias e táticas para a segurança digital feminista ${ }^{7}$; SaferNudes; Chupadados'; Manual Zen y el arte de que la tecnología trabaje para ti" ${ }^{10}$; Faça sua Fuxico Box ${ }^{11}$ são alguns dos exemplos de produções do tipo tecidas em rede.

Produção de hardwares e softwares livres - usamos os termos software e hardware livre e/ou de código aberto para designar, basicamente, o conjunto de tecnologias cujas licenças autorais permitem que qualquer pessoa possa usá-las, alterá-las $e$ compartilhá-las de acordo com suas necessidades. No caso de coletivas hackfeministas brasileiras, as iniciativas mais comuns compreendem a construção de roteadoras, servidoras, redes comunitárias para fornecimento de serviços dentro e fora da internet, tais como: hospedagem de e-mails, websites, repositórios de arquivos multimídia e chats para assegurar o intercâmbio de conteúdos sensíveis e a perspectiva de autonomia tecnológica. Além de tais procedimentos, é possível notar uma crescente preocupação com a raspagem $e$ produção de dados sociodemográficos, com objetivos que vão desde preencher lacunas acadêmicas - vide o relatório produzido a partir da análise de dados da campanha \#primeiroassedio, que revelou ser 9,7 a idade média da primeira experiência de assédio entre as

${ }^{6}$ https://ciberseguras.org/materiales/cibermujeres-curricula-de-capacitacion-enseguridad-digital-holistica-para-defensoras-de-derechos-humanos/, elaborado por Cl4ndestina (Brasil), Ciberfeministas GT (Guatemala), Derechos Digitales (ChileMéxico), Dominemos laTecnología- APC, Luchadoras (México), Nodo Común (Bolivia) e SocialTIC (México), uma das ações que denotam certa articulação em nível de América Latina desses grupos.

7 http://www.cfemea.org.br/index.php/autocuidado-e-cuidado-entreativistas/nossa-abordagem

8 https://www.codingrights.org/safernudes/

9 https://chupadados.codingrights.org/suruba-de-dados/

${ }^{10} \mathrm{https} / / /$ gendersec.tacticaltech.org/wiki/index.php/Complete_manual/es

${ }^{11} \mathrm{http}: / /$ redeautonomafeminista.org/fuxico/suafuxico.html 
declarantes (Bello, 2015); até chamar a atenção da opinião pública e Estado para a necessidade de políticas específicas para determinados segmentos vulnerabilizados - ilustra isso o mapa interativo da violência de gênero, da campanha Take back the tech $^{12}$.

O desenvolvimento de soluções voltadas para fazer frente à mineração de dados corporativa tem gerado experiências como o fuzzify.me $e^{13}$, "uma extensão de navegador [...] que ajuda as pessoas a impedir futuros anúncios direcionados $e$ a obter transparência na plataforma de anúncios do Facebook' (CodingRights, 2019, online). Outro processo curioso é a ressignificação que hackfeministas têm feito do uso dos bots (robôs). Muito utilizados por homens expertos da computação para trolagem, assédio e perseguição de mulheres, os bots têm assumido novos objetivos nas mãos das coletivas investigadas. Exemplo disso é Beta, "uma robô feminista até o último código" (Nossas, 2019, online), que nada mais é do que um software utilizado para auxiliar mulheres e na mobilização e monitoramento dos processos de regulamentação das leis de seus interesses.

O que se percebe dessas ações mapeadas é um processo de constituição ativista onde o cuidado assume lugar central, que visa dar respostas às condições de vulnerabilidade, adversidade $e$ precarização que se encontram as mulheres nos ambientes tecnológicos. Ou seja, diferente dos entendimentos acerca de liberdade e autonomia que coletivos hackers masculinos possam pleitear para as relações sociotécnicas em nosso tempo sustentados num ethos neoliberal que valoriza a autodeterminação, os saberes técnicos $e$ a independência de qualquer autoridade institucional (Toombs, Bardzell e Bardzell, 2015), como vamos argumentar adiante, os entendimentos de autonomia e liberdade das mulheres vêm sendo construídos a

\footnotetext{
${ }^{12}$ https://www.takebackthetech.net/mapit/main?l=lg\&l=pt_BR.

${ }^{13} \mathrm{https} / /$ www.codingrights.org/apresentamos-o-fuzzify-me-ferramenta-que-ajudaa-impedir-anuncios-direcionados-no-facebook/
} 
partir das contingências que seus corpos enfrentam nessas estruturas sociotécnicas contemporâneas.

\section{A ética hacker $e$ o espírito (androcêntrico) do seu tempo}

Etimologicamente, a palavra inglesa hack significa cortar, mas o seu uso atrelado à computação remete ao ambiente de contracultura universitária dos Estados Unidos, do final da década de 1950, principalmente aos estudantes do Massachusetts Institute of Technology (MIT). São esses estudantes (a maioria, homens) os primeiros a utilizar o termo hacker para se referir às pessoas que se dedicam ao desenvolvimento de tecnologias de modo criativo $e$ irreverente. São eles, também, que vão contribuir de modo decisivo para o desenvolvimento da internet (Castells, 2003).

Na década de 1960 o termo rompeu os círculos acadêmicos da tecnologia e se popularizou entre profissionais da área. Desde então, tem passado por diversas ressignificações $e$, mais recentemente, tem sido reivindicado pelas tecnólogas feministas que assinalam os enviesamentos androcêntricos dessas comunidades.

O primeiro autor a apresentar um trabalho expressivo sobre a ética hacker foi o jornalista Steven Levy, no livro Hackers: Heroes of the Computer Revolution (1994). Nele, uma série de conceitos, crenças e costumes que Levy identifica como tacitamente acordados pelos membros dessas comunidades são sintetizados em tom de "manual" para conduta, onde se propõe, dentre outros pontos, que hackers são comprometidos com: o acesso e circulação irrestrita da informação; o uso do computador pessoal como via deste processo libertário; a valorização da filosofia Do It Yourself (DIY), ou seja, se quer alguma coisa, faça você mesmo; a desconfiança das instituições; uma formação autodidata $e$ validada por pares e não por critérios convencionais como diplomas, idade, etnia ou posição social.

Outro trabalho bastante citado nos estudos do campo é a tese The Hacker Ethic and the Spirit of the Information Age, de Pekka Himanen (2001), para quem a ética hacker traduz um novo 
espírito do tempo de nossa sociedade em rede. Ao analisar os princípios que regem a dinâmica de trabalho dos membros da comunidade Linux - a paixão pelo que se faz e a busca por prestígio auferido pelos pares, em detrimento de recompensas financeiras -, Himanen propõe que eles inauguram uma nova etapa de relação de produção que rompe com a ética protestante do capitalismo industrial, proposta por Max Weber, onde o trabalho é visto como um dever. Isso, argumenta o autor, repercute em toda a forma que o trabalho se organiza em nossa época, já que essas novas profissões funcionam cada vez mais sob uma lógica de flexibilização das rotinas de trabalho que, por sua vez, vão se confundir com própria rotina de vida dos indivíduos/trabalhadores.

Já para Manuel Castells (2003), a ética da internet, influenciada principalmente pela ética hacker, resulta da bricolagem de valores e normas articuladas principalmente por mais outros três segmentos sociais: os militares, de onde a internet herdou os esquemas protocolares voltados para segurança; o campo acadêmico, que delineou a arquitetura da rede como um espaço marcado fortemente por relações meritocráticas, onde o prestígio é validado pelo reconhecimento dos pares; o setor do tecnonegócio, representado principalmente pelos empresários do Vale do Silício, que imprimiu na internet características ligadas à inovação, criatividade e eficiência. Por fim, é notório o entusiasmo do sociólogo ao apontar o segmento hacker como o mais importante para a consolidação da cultura digital, justamente por ter sido o que conseguiu absorver todas essas características $e$ amalgamá-las em princípios relacionais. Ou seja, para Castells, foram os hackers os principais mediadores da revolução digital verificada na virada do século e que impactou, de modo basilar $e$ positivo, a sociabilidade de nosso tempo, marcada por mais autonomia e maior fluidez identitária, em detrimento de referenciais modernos calcados em afiliações mediadas por classe, geografia, estado-nação, etc.

As críticas a tais modelos analíticos versam, principalmente, sobre o excessivo tom entusiasta $e$ ao modo binário (crackers $\mathrm{x}$ 
hackers / ética protestante x ética hacker / trabalho x diversão) utilizado para explicar um fenômeno recente, em conformação $e$ que abarca uma miríade de expressões estéticas, ideológicas $e$ políticas (Coleman e Golub, 2008; Rabelo, 2017). Tais críticas, curiosamente, negligenciam a falta de diversidade no seio das comunidades hackers e a dinâmica da distribuição de poder que nelas internamente se estabelecem, problematiza Anikka Richterich (2018).

No Brasil, o debate é ainda mais escasso. No levantamento que faz sobre a produção acadêmica em torno da temática do hackerismo, entre 2000 e 2016, nos anais dos quatro principais congressos científicos do campo da comunicação no país, Leon Rabelo (2017) identifica apenas 18 artigos relacionados. A maioria utiliza os trabalhos de Himanen (2001) e Castells (2003) e nenhum problematiza os imbróglios que envolvem a formação de uma cultura parametrizada por setores da sociedade altamente homogêneos, formados em sua grande totalidade por homens (Wajcman, 2006).

Em consonância com essas críticas é que vemos se amplificar na presente década diversas práticas hackfeministas $e$, com elas, novos aportes sobre o que seriam os contratos sociotécnicos desejáveis para o nosso tempo. Mulheres hackers têm, cada vez mais, ocupado espaços estratégicos do pensar tecnológico, o que é possível aferir tanto pelo aumento significativo nos últimos anos de fóruns ligados à temática do gênero nos eventos e espaços de tecnologia (Araújo, 2018; Richterich, 2018), como na proliferação de coletivos voltados para pensar a relação tecnologia e gênero (Reis e González Ramos, 2019) ou mesmo pelo aumento da visibilidade que pautas feministas têm assumido na internet (Reis e Natansohn, 2017). Isso pode ser verificado, também, no crescimento de investigações e no modo como têm se deslocado as problemáticas endereçadas a este campo, que paulatinamente migram de uma atenção excessiva acerca da ausência de mulheres na tecnologia, para investigar os novos significados que espaços generificados têm tensionado para o fazer tecnológico (Haché, Cruells e Bosch, 2013). Tais pesquisas 
têm encontrado neste contexto de novos tensionamentos identitários, principalmente na proliferação de grupos hackers constituídos por mulheres, campo fértil para a reflexão acerca dos dilemas éticos que emolduram o cenário digital contemporâneo.

Os estudos de Souphie Toupin (2014), sobre espaços hakerfeministas nos Estados Unidos, identificam que nesses grupos as práticas de "hackeamento" assumem novos significados e urgências, orientadas para o levantamento dos problemas sistêmicos e estruturais que se manifestam nas sociedades e na tradição tecnológica (racismo, sexismo, transfobia, queerfobia, etc.) em contraposição à ênfase autocentrada e libertária de produção de conhecimento compartilhado das comunidades hackers, geralmente masculinizadas.

Já Débora Oliveira (2017) sugere que os regimes que referendam a hegemonia do modelo corporativo da internet têm íntima relação com a mesma lógica que invisibiliza corpos subalternizados, como mulheres, sujeitos racializados e indivíduos não binários. Nessa mesma perspectiva, outras pesquisadoras (Araújo e Gitahy, 2016; Fox, Ulgado e Rosner, 2015) vão mostrar como a discussão sobre anonimato $e$ visibilidade hacker se complexifica a partir das contingências de gênero. Enquanto os tradicionais grupos hackers se constituem a partir da reivindicação do anonimato individual e da exposição das instituições, para hackfeministas esse processo é altamente ambíguo. Se, por um lado, é importante visibilizar o trabalho realizado por mulheres para lutar contra a sub-representação e exploração de seu trabalho intelectual nos ambientes tecnológicos, por outro, mostrar-se significa lidar com oportunidades de vigilância e uma série de estratégias de silenciamento e violências (trolagem, derrubada e seqüestro de páginas na web, dogpiling, doxing, dentre outras), que geralmente surgem como resposta a mulheres ou coletivas que assumem algum tipo de visibilidade pública, principalmente ativistas. Isso nos faz lembrar uma máxima harawayana: "a autoinvisibilidade de alguns se mantém sempre graças à invisibilidade pública de outros" (Haraway, 2004:57). Ou seja, o efeito colateral gerado pela autoinvisibilidade seletiva $e$ 
masculinista moderna é, pois, a produção de indivíduos marcados, de outros desviantes que "não se encaixam nas articulações semiótico-materiais contingentes" (Haraway, 2004:57).

$\mathrm{O}$ que se percebe dessa nova cena hackfeminista, tanto no plano teórico como do ativismo, é que valores tradicionalmente caros à cultura hacker - tais como liberdade de expressão, autonomia, meritocracia e abertura - passam a ser revistos, questionados e posicionalizados (Haraway, 2004) a partir das experiências de gênero, raça e classe de suas integrantes. A esses fatores, junta-se o desejo de mulheres de "codificar em paz", sem ter que lidar constantemente com situações de assédio ou de questionamento de suas legitimidades profissionais. Assim o expressam Lili_Anaz e Natasha Akhmatova (2018), num textomanifesto político e poético escrito a partir
(...) da cumplicidade algorítmica a quatro mãos e em portuñol-espanglish entre México e Brasil, de maio a outubro de 2017, principalmente por meio de um longo pad $<3$, chat, notas de voz, palavra falada, notas em vídeo, imagens, insônias, debrayes, e-mails, pausas, chamadas, músicas $e$, sobretudo, "vontades"... Neste manifesto - $e$ mais do que tentar explicar o que é ou o que não é um algoritmo - queremos reescrever nossas próprias formas de intervenção e resistência a partir de uma postura política hackfeminista: queremos resistir a qualquer infraestrutura que permita e reproduza opressão, discriminação $e$ misoginia, através de nossos corpos-territórios-algoritmos em qualquer espaço em que habitemos dentro ou fora da Internet (Lili_Anaz e Akhmatova, 2018, online, tradução nossa).

\section{Uma nova (ética da) internet é possível?}

A ideia de pensar uma ética racional, individual $e$ autônoma, tal qual tem sido tratada a ética hacker $e$ a ética da cultura das redes digitais, vem de uma tradição teórico-jurídica que embasa as teorias da moral $e$ influenciou algumas das principais correntes filosóficas que se fizeram hegemônicas no 
século XX. Esse modelo universalista, que privilegia aspectos ligados ao exercício da vida pública - igualdade, discursividade, universalidade e autonomia -, em detrimento de valores que permeiam a vida privada - o (des)afeto, o cuidado $e$ as condições de vulnerabilidade social incutidas nas relações - encontrou no campo dos estudos filosóficos feministas algumas de suas críticas mais contundentes, sobretudo por autoras do campo da Ética Feminista dos Cuidados (Carol Gilligan, 1982; 2013; Joan Tronto e Berenice Fisher, 1990; dentre outras). Para essas filósofas, o modelo teórico-jurídico ratifica processos epistemológicos modernos que tornaram legítimo o afastamento das mulheres do âmbito público.
(...) aquelas relações impessoais e passíveis de escolha tratadas pelas teorias morais tradicionais representam apenas um tipo de contexto em que é possível exercer a moralidade. Os outros contextos invisibilizados - contextos de cuidado historicamente relegados à mulher -, (...) são precisamente aqueles que sustentam a própria existência de um âmbito público $e$ impessoal em que pode haver interação moral. Outras atividades de manutenção $e$ suporte social, que são claramente influenciadas por classe e raça, são igualmente invisibilizadas, assumindo-se assim que as questões que permeiam a vida de mulheres, pessoas escravizadas e trabalhadores não são importantes no campo da moral (Possebon, 2015:168).

Numa contemporaneidade digitalizada, onde as bordas entre público e privado se veem cada vez mais borradas, a perspectiva de uma única construção ética para analisar grupos $e$ contextos distintos, mostra-se cada vez mais questionável. Por tudo isso, argumentamos que aspectos da ética do cuidado (Gilligan, 1982; 2013) estão sendo apropriados e transformados pelas hackfeministas, de formas diversas e com um olhar interseccional. Como o definem Hirata e Debert (2016:7), "cuidado é um termo utilizado para descrever processos, relações e sentimentos entre pessoas que cuidam umas das outras, como 
também de seres vivos e até mesmo de objetos, cobrindo várias dimensões da vida social".

O cuidado, enquanto conceito, tem como marco a obra In a Different Voice, de Carol Gilligan (1982). Nela, a autora critica o caráter androcêntrico das teses tradicionais, que subscrevem a conduta moral e ética como valores universais. Uma outra racionalidade, assentada no que poderia se chamar, generalizando, certa cultura feminina, guia as condutas morais das mulheres, baseada nas relações interpessoais e em valores como interdependência, comunicação, responsabilidade e cuidado, afirma Gilligan (1982). A partir dessa obra se instalou o debate que envolve não apenas as questões éticas, como também sociais $e$ econômicas e, ainda, as políticas estatais do bem-estar social.

A discussão sobre o sujeito do cuidado está vinculada com as questóes acerca da relação dependência/autonomia e a tendência a se menosprezar a dependência humana e as práticas sociais que produzem vulnerabilidades. $O$ investimento na socialização masculina busca, de um lado, o desenvolvimento da autonomia e, de outro, um pensamento liberado dos afetos, o que tem relação quase direta com as relações violentas. $\mathrm{O}$ ponto de vista da ética feminista inaugurada por Gilligan é diferente das tradicionais teorias morais da filosofia - baseadas no ideal do indivíduo autônomo - porque considera as experiências das mulheres e postula que o gênero constitui uma diferença relevante entre as pessoas. Gilligan, a partir da revisão crítica dos trabalhos de Kohlberg (1992, apud Gilligan, 2013), trouxe o que chamou de ética do cuidado, de onde inicia um debate que coloca em evidência a existência de duas éticas: uma, para o público, chamada ética da justiça; e outra ética para o familiar, o doméstico e íntimo, a do cuidado, junto a uma ideia diferenciada de self, expressa em dois modos de narrar sobre problemas morais e sobre a relação entre o eu e o outro (Zirbel, 2016). A ética da justiça, predominante a nível simbólico, baseia-se em indivíduos em relação, mas sem vínculos, completamente independentes, associada ao mundo do masculino, androcêntrica, tal como a ética 
hacker tem sido postulada por muitos autores (Levy, 1994; Himanen, 2001; Castells, 2003).

Apesar das diversas críticas à obra de Gilligan essa noção reivindica uma abordagem mais realista para um sujeito que se constrói socialmente e se define no contexto das relações com a/os outra/os. A ética feminista distingue-se por explorar as formas pelas quais a desvalorização cultural das mulheres e do feminino se reflete e se racionaliza nos conceitos e métodos principais da filosofia moral (Jaggar, 2014). Longe de pensarmos a ética feminista $e$ os cuidados das pessoas e dos objetos como exclusividade das pessoas do sexo feminino, pelo contrário, acreditamos que seja parte de uma moralidade mais universal, uma vez que as exigências sobre cuidados "e o desenvolvimento das qualidades ou virtudes que comumente lhes são associadas (como empatia, compaixão, capacidade de percepção e resposta, etc.) são acessíveis e desenvolvidas tanto em homens quanto em mulheres" (Zirbel, 2016:24).

Aderimos à perspectiva que vê nos cuidados uma prática social, onde se materializam não apenas relações de gênero, senão de classe e raça. A pesquisa PNAD Contínua (IBGE, 2018) mostra que a participação das mulheres supera a dos homens em algumas profissões culturalmente identificadas como femininas $e$ de cuidados e associadas a menores salários. A maior disparidade se encontra na categoria dos/as trabalhador/as domésticas/os, na qual $92,3 \%$ são mulheres negras. Mas elas também predominam no magistério, nas enfermarias e na assistência social, onde a maioria são, também, mulheres negras.

De amas a babás, mulheres negras permanecem responsáveis pela higiene, alimentação e primeira educação de meninas/os da elite. Prevalece a relação entre a ama do período colonial e a cuidadora dos dias atuais que substitui a mãe biológica branca no cuidado de suas/seus filhas/os para que esta possa ascender na carreira (Chaves, 2014).

O mesmo cabe para as profissões tecnológicas, onde as mulheres que atingem o "teto de vidro" são majoritariamente cis e 
brancas, as mulheres negras e lésbicas são muito poucas $e$ a presença de indígenas é irrisória. A pesquisa QuemcodaBr (PretaLab e Thoughtworks, 2019) reporta que no universo das instituições ligadas à tecnologia no país, cerca de $32,7 \%$ não possui sequer uma pessoa negra empregada e $95,9 \%$ não apresentaram indígenas. Nas que possuem mulheres e homens negros em seu quadro de colaboradoras/es $(68,5 \%)$, tais indivíduos não contabilizam mais que $10 \%$ das equipes. A pesquisa mostra, ainda, que todas essas pessoas sofrem da falta de isonomia salarial, um cenário que chama atenção para a pertinência das articulações interseccionais pleiteadas pelas hackfeministas.

Enquanto o cuidado sempre foi considerado reprodutivo $e$ não produtivo, cabe pensar que estas formas produtivas $e$ proativas de cuidados digitais, promovidas pelas hackfeministas, tiram o cuidado do âmbito doméstico e o desloca para as práticas tecnológicas que hoje em dia perpassam todos os âmbitos relacionais, não podendo mais ser caracterizadas como exclusivas da esfera privada e, menos, meramente reprodutivas.

É verdade que há certo risco de que estas práticas hackfeministas reforcem a feminilidade do cuidado, essencializando as hierarquias de gênero na divisão sexual do trabalho, na medida em que se continua a hipertrofiar a dimensão emocional e afetiva, associada ao feminino, o que não deixa de ser problemático. Para usar o termo cuidado, sem cair no essencialismo de gênero, seria preciso ter em conta as suas conotações históricas, culturais e de gênero, conotações estas que têm contribuído também o próprio feminismo. Como adverte Esteban (2017), em relação aos cuidados domésticos, a ética do cuidado pode levar a pensar que o melhor cuidado é aquele onde os sentimentos estão presentes (ou seja, através de amigas mulheres ou família), o que seria contraditório com a defesa de serviços públicos suficientes e de qualidade ou humanizados, e de relações trabalhistas mais simétricas. Neste mesmo sentido, as críticas a Gilligan vão em três direções principais: 
(...) consideram que esse tipo de desenvolvimento da autora sobre as diferenças entre os sexos reforça a ideia de uma postura essencialista; a autora, ao trabalhar com "a mulher", como uma categoria englobadora, subestima as diferenças sociais, econômicas e culturais, entre outras diferenças que dão sentidos muito distintos à experiência feminina; e, que as concepções da autora seriam, no limite, tributárias do que Nietzsche denomina a moral dos escravos, posto que a subserviência das mulheres pode ser interpretada como uma virtude (Hirata e Debert, 2016:9).

Contudo, o que as hackfeministas demandam e colocam em evidência é que as práticas de cuidados tecnológicos sejam parte dos protocolos de comunicação digital, tal qual acontece quando denunciam a coleta massiva de dados, a vigilância; ou quando desenvolvem protocolos, códigos e dispositivos seguros. Vemos aí uma superação do binômio ética do cuidado/ética da justiça, pois o que se demanda são cuidados encarnados na materialidade sociotécnica e em leis e políticas públicas que preservem a privacidade $e$ os direitos de todos os humanos nas comunicações digitais, independentemente do gênero.

Por outra parte, algumas coletivas brasileiras contam com a participação de pessoas trans e não binárias, pelo que se nota uma tentativa de distanciamento do essencialismo de gênero que ronda a perspectiva do cuidado.

Encontros transhackfeministas internacionais vêm sendo realizados desde 2014. O primeiro encontro transhackfeminista, chamado THF! foi realizado na Catalunha, Espanha, em 2014; o segundo, em Puebla, México, em 2015,e o terceiro, em Montreal, Canadá, em 2016. Na convocatória do último se afirma que:

O evento tem como objetivo abordar a falta de mulheres, queer, trans e da diversidade no campo tecnológico, em geral, e no hacking, em particular. Concretamente, pretende-se criar uma comunidade que avalie de forma crítica as narrativas hegemônicas em torno das tecnologias, os aspectos da modernidade e dos pressupostos ocidentais 
subjacentes e seus traços capitalistas inerentes, entre outros (THF, 2016, online, tradução nossa).

Ainda que a participação brasileira nestes eventos seja escassa - apenas duas representantes de coletivas - e ainda que não haja consenso sobre o uso desta denominação, observamos que o debate está colocado e permeia os círculos feministas, também bastante tensionados pelas transfobias.

Politizar os cuidados, desde uma perspectiva hackfeminista crítica, significa pensar estratégica e politicamente a internet, as tecnologias digitais e o lugar que mulheres e pessoas dissidentes ocupam na ecologia do sistema, levando em conta seu lugar social, racial, de classe e de gênero, suas potências e possibilidades. "Cuidar possui uma dimensão subjetiva que envolve relações e afetos entre quem cuida e é cuidada/o", diz Marjorie Chaves (2014).

Os afetos, na ética hackfeminista do cuidado, adquirem relevância e viram código; as emoções são parte da conduta e do juízo moral, que não pode ser compreendido como objetivo $e$ imparcial, senão localizado, situado. Amor e desamor, confiança e desconfiança, altruísmo e egoísmo, dependência e independência, emoções, em geral, não podem estar apenas relacionadas com a esfera do íntimo e desconectadas das relações sociotécnicas num contexto de desigualdade estrutural entre gêneros, classes e raças, ou consideradas como apolíticas.

Entender quais disputas normativas se estabelecem nesse campo, quais as materialidades por elas afetadas $e$ os entes desencaixados e, aqui incluímos nós, (des)cuidados que elas produzem, mostra-se um trabalho urgente num contexto onde novos paradigmas epistemológicos e econômicos têm sido engendrados a partir de processos de mediação algorítmica, que apontam para o aprofundamento de desigualdades sociais, ameaça os processos democráticos e minimiza o papel do Estado nos processos de regulação das relações produtivas (Zuboff, 2015). 


\section{Considerações finais}

O objetivo deste artigo foi trazer uma primeira aproximação teórica ao fenômeno dos cuidados digitais, emergente nesta última década e próprio do feminismo em redes digitais, que nomeamos como hackfeminismo. O fazemos desde uma perspectiva teórica $e$ política que alia a teoria feminista sobre a tecnologia à ética feminista dos cuidados, à vez que desafia os pressupostos da ética hacker. Revisamos brevemente os princípios da ética hacker e da ética dos cuidados e revisamos as implicações sociotécnicas dos enfoques androcêntricos. Primeiro, mapeamos as estratégias de tecnoativismo realizadas como resposta aos processos massivos de coleta de dados e vigilância massiva, que parecem contribuir para as assimetrias sociais e para novas expressões de violência de gênero. Logo depois, as interpretamos à luz dos debates sobre a ética do cuidado e da ética hacker.

Expusemos algumas das iniciativas em cuidados digitais que mais vêm assumindo relevância nas redes feministas digitais $e$ explicamos seus propósitos e motivações: por um lado, buscam dar respostas à violência de gênero, nativa das relações patriarcais, que se atualiza com formatos e características diversas nos contextos de interação online e que gera consequências danosas para as mulheres e os sujeitos subalternizados pela sua identidade de gênero e raça. Por outro lado, trouxemos o debate ao redor da colonização da internet pelos interesses do capital, que redunda em rastreamento massivo, comercialização de nossos dados e vigilância, gerando situações de vulnerabilidade da intimidade e da privacidade para usuárias de internet e seus aplicativos, que caracterizamos como um novo tipo de violência, oculta e sorrateira por apresentar-se incutida nos códigos opacos.

Revisamos estudos que apontam para a formação de um novo hub de mulheres tecnólogas, que têm primado por intensificar a interlocução entre movimento feminista $e$ movimento hacker, com ênfase na produção de tecnologias autônomas. Tais grupos, apesar de lógicas operacionais distintas trazem em comum a luta pela diversidade de gênero nos espaços de produção de 
infraestruturas de TICs. A maior parte surgiu a partir do ano de 2015, o que corrobora com a ideia de que estamos diante de um fenômeno recente e ainda em processo de consolidação. É possível perceber que operam dentro de uma lógica com muitas das características aqui atribuídas à ética hacker - tais como a priorização de software livre, da criptografia, da produção compartilhada do conhecimento, etc.-, mas que, para além de uma demanda instrumental, voltam suas energias para pensar seus direitos digitais, bem como desenvolver respostas às problemáticas que lhes atravessam nessa nova etapa de digitalização das relações produtivas, sociais e simbólicas. Ao hackear as generificações incutidas nos códigos sociotécnicos, esses grupos mostram que nem todo espaço que se diz aberto $e$ horizontal é, necessariamente, um locus que privilegia a inclusão $e$ equidade, nem tampouco hackers devem ser avaliados apenas pela beleza de seus códigos, como apregoava Levy (1994).

As práticas aqui escrutinadas falam, ainda, de processos constitutivos que nos convocam a pensar a implosão, no sentido harawayano, de uma universalização das normas de condutas de nosso tempo. Há que se levar em conta que o apelo por trabalho compartilhado, meritocracia e autonomia, que orienta a agenda política dos tradicionais espaços hackers, tem pontos de partida $e$ chegada totalmente distintos (e certamente relevantes) que os aportados pelas experiências dessas ativistas aqui retratadas. Mas é importante perceber como a hegemonia da moral de determinado grupo social produz todo um processo histórico de assimetria que é importante ser problematizada.

Assim, é importante perceber, por exemplo, como a perspectiva de trabalho colaborativo apregoada originalmente pela cultura hacker tem, muitas vezes, significado para mulheres ver seus trabalhos cooptados e explorados por homens (Henry, 2014). Igualmente, a ideia de abertura praticada tão corriqueiramente nos espaços hackers, ou seja, de acolher indiscriminadamente todo tipo de gente, com todo tipo de perspectiva de mundo, tem posto de lado o entendimento de que a igualdade pode incidir como "tirania" sobre segmentos historicamente vulnerabilizados, tais 
como mulheres negras e pessoas trans. É importante perceber que para mulheres, na maior parte das vezes, hackear não tem a ver com uma aventura prazerosa ou um ato de transgressão $e$ enfrentamento das estruturas estatais e do mercado, conforme apontam as etnografias hackers masculinas (Jordan e Taylor, 1998; Coleman e Golub, 2008). Para essas mulheres, hackear significa um processo de apropriação de estruturas capazes de transformar as relações de poder ou mesmo o resultado da necessidade de criar respostas aos principais dilemas que as têm acometido. Daí a necessidade de uma ética do cuidado.

No contexto de resistência feminista à ofensiva conservadora $e$ antidireitos que atinge estas latitudes, o cuidado digital entre ativistas vêm colocar em cena a politização, racialização e generificação da tecnologia. Os cuidados digitais, pois, não são tanto um problema técnico como um desafio às formas culturais através das quais nos integramos no mundo, pensamos nossa relação com as tecnologias e questionamos que lugar ocupamos nesta imensa vizinhança que é o mundo em rede, com seus centros e periferias.

\section{Referências bibliográficas}

ARAÚJO, Daniela. Feminismo e cultura hacker: intersecções entre política, gênero e tecnologia. Tese de doutorado, Instituto de Geociências, Unicamp, 2018.

ARAÚJO, Daniela; GITAHY, Leda. Mulheres e a segurança da informação: a trajetória de um hackerspace feminista no Brasil. IV Simpósio Internacional Lavits - Nuevos paradigmas de la vigilancia? Miradas desde América Latina, Buenos Aires, 2016, pp. 1-9. [http://lavits.org/wp-content/uploads/2017/08/P8 Ara\%C3\%BAjo.pdfacesso em 16 jul 2019]

BELLO, Luíse. Uma Primavera sem fim. Think Olga, São Paulo-SP, 2015. [http://thinkolga.com/2015/12/18/uma-primavera-sem-fim acesso em 14 jul 2019].

CASTELLS, Manuel. A galáxia da Internet: reflexões sobre a Internet, os negócios e a sociedade. Rio de Janeiro-RJ, Editora Zahar, 2003. 
CHAVES, Marjorie. De ama a baba: mulheres negras e a racialização do cuidado. Blogueiras

Negras.

2014 [http://blogueirasnegras.org/2014/09/30/de-ama-a-baba-mulheresnegras-e-a-racializacao-do-cuidado/ - acesso em 27 mai 2019].

CODINGRIGHTS. Apresentamos o Fuzzify.me, ferramenta que ajuda a impedir anúncios direcionados no Facebook. CodingRights, 2019 [https://www.codingrights.org/apresentamos-o-fuzzify-me-ferramentaque-ajuda-a-impedir-anuncios-direcionados-no-facebook/ - acesso em 15 mai 2019]

CODINGRIGHTS; INTERNETLAB. Violências contra mulher na internet: diagnóstico, soluções e desafios. Contribuição conjunta do Brasil para a relatora especial da ONU sobre violência contra a mulher. São Paulo-SP, $2017 \quad$ [http://www.internetlab.org.br/wpcontent/uploads/2017/11/Relatorio_ViolenciaGenero_ONU.pdf acesso em 23 mai 2019].

COLEMAN, Gabriela; GOLUB, Alex. Hacker practice: Moral genres and the cultural articulation of liberalism. Anthropological Theory, 8, 3, 2008, pp. 255-277 [https://doi.org/10.1177\%2F1463499608093814 - acesso em 02 out 2020].

DERECHOS DIGITALES. Latin America in a glimpse. Género, feminismos $e$ internet en América Latina. Internet Governance Forum, Suiza, 2017 [https://www.derechosdigitales.org/publicaciones/latin-america-in-aglimpse-2017-2/- acesso em 15 jun 2019].

ESTEBAN, Mari L. Los cuidados, un concepto central en la teoría feminista: aportaciones, riesgos y diálogos con la antropología. QuAderns-e, n. 22(2), Barcelona, ICA, 2017, pp.33-48 [https://www.raco.cat/index.php/QuadernseICA/article/view/333111 acesso em 02 out 2020].

FOX, Sarah; ULGADO, Rachel; ROSNER, Daniela. Hacking culture, not devices: Access and recognition in feminist hackerspaces. CSCW'15: Proceedings of the 18th ACM Conference on Computer Supported Cooperative Work \& Social Computing, New York, ACM Press, 2015, pp. 56-68 [Doi:10.1145/2675133.2675223 - acesso em 2 jun 2019].

GILLIGAN, Carol. In a different voice. Cambridge, Harvard University Press, 1982. 
GILLIGAN, Carol. La ética del cuidado. Barcelona, Fundació Victor Grífols i Lucas, 2013 [http://www.secpal.com/\%5CDocumentos\%5CBlog\%5Ccuaderno30. pdf - acesso em 19 jun 2019].

HACHÉ, Alex; CRUELLS, Eva; BOSCH, NúriaV. Eu programo, tu programas, ela hackea: mulheres hackers e perspectivas tecnopolíticas. In: NATANSOHN, Graciela. (Org.). Internet em código feminino: teorias e práticas, 2.ed. revista e ampliada, Buenos Aires, La Crujía, 2013 [http://gigaufba.net/internet-em-codigo-feminino/ acesso em 02 out 2020]

HARAWAY,Donna.Testigo_Modesto@Segundo_Milenio.HombreHembr a(c)_Conoce_Oncoratón ${ }^{\circledR}$. Feminismo y tecnociencia. Barcelona, Editorial UOC̄, 2004 [1997].

HENRY, Liz. The Rise of Feminist Hackerspaces and How to Make Your Own. Model View Culture: Technology, culture and diversity media, 2014 [https://modelviewculture.com/pieces/the-rise-of-feministhackerspaces-and-how-to-make-your-own - acesso em 04 jun 2019].

HIMANEN, Pekka. The hacker Ethic and the Spirit of the Information Age.New York, Random House, 2001.

HIRATA, Helena; DEBERT, Guita. Apresentação. Dossiê Gênero e Cuidado. cadernos pagu (46), Campinas-SP, Núcleo de Estudos de Gênero-Pagu/Unicamp, janeiro-abril de 2016, pp.7-15 [doi:10.1590/18094449201600460007 - acesso em 18 mai 2019].

IBGE, Instituto Brasileiro de Geografia e Estatística. No Dia da Mulher, estatísticas sobre trabalho mostram desigualdade. 2018 [https://agenciadenoticias.ibge.gov.br/agencia-noticias/2012-agenciade-noticias/noticias/20287-no-dia-da-mulher-estatisticas-sobretrabalho-mostram-desigualdade.html - acesso em 27 mai 2019].

IPEA, Instituto de Pesquisa Econômica Aplicada; FBSP, Fórum Brasileiro de Segurança Pública. Atlas da Violência 2019. Brasilia, 2019 [http://www.ipea.gov.br/portal/images/stories/PDFs/relatorio institucio nal/190605_atlas_da_violencia_2019.pdf - acesso em 29 jul 2019].

JAGGAR, Alisson. Ética Feminista. Debate Feminista (25), 49, Abril 2014 ,

[http://www.filosoficas.unam.mx/ gmom/etica2/Jaggar-

pp. $8-44$

Eticafeminista.pdf - acesso em 02 out 2020] 
JORDAN, Tim; TAYLOR, Paul. A Sociology of Hackers. The Sociological Review.46, 4, Oxford, Blackwell Publishers, 1998 [https://journals.sagepub.com/doi/10.1111/1467-954X.00139 - acesso em 02 out 2020].

LEVY, Steven. Hackers: Heroes of the Computer Revolution. New York, Doubleday, 1994. December 1990 ACM SIGCAS Computers and Society 21(1), pp.6-17 [DOI: 10.1145/122246.122248 - acesso em 02 out 2020].

LILI_ANAZ. AKHMATOVA, Natasha. [Edición especial] Manifiesto por algoritmias hackfeministas. GenderIT.org, 2018 [https://www.genderit.org/node/5154 - acesso em 15 jun 2019].

NATANSOHN, Graciela. (Org.). Internet em código feminino: teorias e práticas, 2.ed. revista e ampliada, Buenos Aires, La Crujía, 2013 [http://gigaufba.net/internet-em-codigo-feminino/ - acesso em 02 out 2020].

NATANSOHN, Graciela; GOLDSMAN, Florencia. Violencia de género expandida: vigilancia y privacidad en red. Fronteiras - estudos midiáticos, 20(3), Unisinos, São Leopoldo-RS, 2018, pp.378-389 [doi: 10.4013/fem.2018.203.10 - acesso em 22 mai 2019].

NOSSAS. Beta, uma robô feminista até o último código. 2019 [https://www.beta.org.br/ - acesso em 20 jul 2019].

O'NEIL, Cathy. Armas de Destrucción Matemática. Como el Big Data aumenta la desigualdad y amenaza la democracia. Madrid, Capitán Swing, 2017.

OLIVEIRA, Débora. Redes comunitárias e regimes de invisibilidade de infraestruturas e corpos. V Simpósio Internacional Lavits - Vigilancia, Democracia y Privacidad en America Latina. Campinas-SP, 2017 [http://lavits.org/wp-content/uploads/2018/04/40-D\%C3\%A9boraPrado-de-Oliveira.pdf - acesso em 02 mai 2019].

OLIVEIRA, Ellen. Mulheres negras vítimas de violência obstétrica: estudo em um hospital público de Feira de Santana-Bahia. Dissertação de Mestrado, Instituto Nacional de Saúde da Criança, Mulher e Adolescente Fernandes Figueira, Rio de Janeiro-RJ, 2017.

PEW RESEARCH CENTER. Code-Dependent: Pros and Cons of the Algorithm Age. Pew Research Center/ Internet Technology, 
Washington-DC, 2017 [http://www.pewinternet.org/2017/02/08/codedependent-pros-and-cons-of-the-algorithm-age - acesso em 14 jan 2019].

POSSEBON, Lurian. O modelo expressivo-colaborativo: uma alternativa feminista à ética tradicional. Kínesis (15), São Paulo-SP, 2015,pp.164-186

[https://www.marilia.unesp.br/Home/RevistasEletronicas/Kinesis/12 lu rianpossebon.pdf - acesso em 03 jun. 2019].

PRETALAB; THOUGHTWORKS. \#QuemCodaBR. 2019 [https://assetsglobal.websitefiles.com/5b05e2e1bfcfaa4f92e2ac3a/5d671881e1161a6d2b8eb78b Pesquisa\%20QuemCodaBR.pdf - acesso em 8 set 2019].

DE LA BELLACASA, Maria Puig. Matters of Care in Technoscience: Assembling Neglected Things. Social Studies of Science, 41, 1, 2011 [doi:10.1177/0306312710380301- acesso em 5 mai 2019].

RABELO, Leon. O que é um Hacker: trajetórias de um termo em uso. Anais do XXVI Encontro Anual da Compós, São Paulo-SP, 2017 [http://www.compos.org.br/data/arquivos_2017/trabalhos_arquivo_9F MF8CGFET560LOD5UTQ_26_5823_21_02_2017_14_00_18.pdf acesso: 5 jul 2019].

REIS, Josemira; GONZÁLEZ RAMOS, Ana María. Mujeres hackers y sus nuevos espacios: Un panorama de las experiencias engendradas en el Brasil actual. Llibre d'actes Congrés Dones, Ciència i Tecnologia, WSCITECH19, 1, 1, Barcelona, 2019 [https://www.omniascience.com/books/index.php/proceedings/catalog/ view/107/459/889-1 - acesso em 10 jul 2019].

REIS, Josemira; NATANSOHN, Graciela. Com quantas hashtags se constrói um movimento? Tríade - Revista de Comunicação, Cultura e Mídia 5, 10, 2017, pp.113-130 [http://periodicos.uniso.br/ojs/index.php/triade/article/view/3096 acesso em 02 out 2020].

RICHTERICH, Annika. Tracing controversies in hacker communities: ethical considerations for internet research. Information, Communication \& Society 23, 1, 2018, pp.76-93 [doi: 10.1080/1369118X.2018.1486867-acesso em 10 jun 2018]. 
SILVEIRA, Sergio Amadeu. Ciberativismo, cultura e o individualismo colaborativo. Revista USP (86), São Paulo-SP, 2010, pp.28-39 [http://www.revistas.usp.br/revusp/article/view/13811 - acesso em 02 out 2020].

TGEU. Transrespect Versus Transphobia World Wide. Transgender Europe, 2019

[https://transrespect.org/wpcontent/uploads/2018/11/TvT TMM TDoR2018 Tables_EN.pdf acesso em 17 ago 2019].

THF. Secondo Encuentro Transhackfeminista - Convocatoria, 2016 [https://transhackfeminist.noblogs.org/convocatoria-thf2016/ - acesso em 5 jun 2019].

TOOMBS, Austin; BARDZELL, Shaowen; BARDZELL, Jeffrey. The Proper Care and Feeding of Hackerspaces: Care Ethics and Cultures of Making. CHI'15: Proceedings of the 2015 CHI Conference on Human Factors in Computing Systems. New York, ACM Press, 2015, pp. 629-638 [doi:10.1145/2702123.2702522 - acesso em 11 ago 2019].

TOUPIN, Sophie. Feminist hackerspaces: The Synthesis of Feminist and hacker Cultures. Journal of Peer Production (5), 2014 [http://peerproduction.net/editsuite/wp-content/uploads/2014/09/ahackerspace-of-ones-own.pdf - acesso em 5 abr 2019].

TRONTO, Joan; FISHER, Berenice. Toward a Feminist Theory of Caring. In: ABEL, Emily; NELSON, Margaret (org.). Circles of Care. New York, SUNY Press, 1990, pp.36-54.

VAN DIJCK, Jose. Confiamos nos dados? As implicações da datificação para o monitoramento social. Revista Matrizes, 11, 1, São Paulo-SP, 2017 [http://www.revistas.usp.br/matrizes/article/view/131620 - acesso em 02 out 2020].

VEGH, Sandor. Classifying forms of offline Activism: the case of cyberprotests against the world banks. In: MCCAUGHEY, Martha; AYRES, Michael D. (org.). Cyberactivism. Online activism in theory and practice. New York, Routledge, 2006, pp.71-97 [doi: 10.11606 acesso em 13 jun 2019].

VICENTIN, Diego. Governança da Internet, Infraestrutura e resistência. IV Simpósio Internacional Lavits - Nuevos paradigmas de la vigilancia? Buenos Aires, 2016 
[http:/lavits.org/wpcontent/uploads/2017/08/P8 Vicentin.pdf - acesso em 7 jul 2019].

WAJCMAN, Judith. El Tecnofeminismo. Madrid, Cátedra, 2006.

ZIRBEL, Ilze. Uma teoria político-feminista do cuidado. Tese de doutorado, Filosofia, Universidade Federal de Santa Catarina, 2016 [https://repositorio.ufsc.br/bitstream/handle/123456789/167820/3399 12.pdf?sequence $=1$ - acesso em 23 mai 2019].

ZUBOFF, Shoshana. Big other: surveillance capitalism and the prospects of an information civilization. Journal of Information Technology (30), 2015, pp.75-89 [doi:10.1057/jit.2015.5 - acesso em 7 ago 2019]. 